\title{
Motivation and response rates in bronchoscopy studies
}

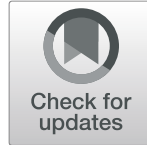

Einar M. H. Martinsen ${ }^{1 *}$, Tomas M. L. Eagan ${ }^{1,2}$, Elise O. Leiten ${ }^{1}$, Eli Nordeide ${ }^{2}$, Per S. Bakke ${ }^{1}$, Sverre Lehmann ${ }^{1,2}$ and Rune Nielsen ${ }^{1,2}$

\begin{abstract}
Background: Bronchoscopy is frequently used to sample the lower airways in lung microbiome studies. Despite being a safe procedure, it is associated with discomfort that may result in reservations regarding participation in research bronchoscopy studies. Information on participation in research bronchoscopy studies is limited. We report response rates, reasons for non-response, motivation for participation, and predictors of participation in a large-scale single-centre bronchoscopy study ("MicroCOPD").

Methods: Two hundred forty-nine participants underwent at least one bronchoscopy in addition to being examined by a physician, having lung function tested, and being offered a CT scan of the heart and lungs (subjects $>40$ years). Each participant was asked an open question regarding motivation. Non-response reasons were gathered, and response rates were calculated.

Results: The study had a response rate just above $50 \%$, and men had a significantly higher response rate than women $(56.5 \%$ vs. $44.8 \%, p=0.01)$. Procedural fear was the most common non-response reason. Most participants participated due to perceived personal benefit, but a large proportion did also participate to help others and contribute to science. Men were less likely to give exclusive altruistic motives, whereas subjects with asthma were more likely to report exclusive personal benefit as main motive.

Conclusion: Response rates of about 50\% in bronchoscopy studies make large bronchoscopy studies feasible, but the fact that participants are motivated by their own health status places a large responsibility on the investigators regarding the accuracy of the provided study information.
\end{abstract}

Keywords: COPD, Clinical research, Motivation, Response rate, Non-response

\section{Introduction}

Although primarily employed as a diagnostic tool, bronchoscopy is useful in studies on airway inflammation, bronchial remodelling, and the airway microbiota. Studies on airway microbiota have so far been relatively low-powered [1-3], and future studies will depend on larger samples. Even if bronchoscopy is associated with a low complication rate [4], some discomfort is inevitable, and potential participants may therefore have reservations [5]. Knowledge on motives for participation and response rates in bronchoscopy studies have the potential to optimise the recruitment process.

\footnotetext{
* Correspondence: einar.martinsen@uib.no

'Department of Clinical Science, University of Bergen, N-5021 Bergen, Norway Full list of author information is available at the end of the article
}

However, there are few studies providing reliable response rates and motives for participation in bronchoscopy studies. A literature review on research bronchoscopy studies included seven relevant studies, and found personal benefit and altruistic reasons to be the most important participation motives, whereas fear of the bronchoscopy was reported as a participation barrier [6]. Response rates from the seven studies varied from 3 to $73 \%$, and no study examined participation among subjects with chronic obstructive pulmonary disease (COPD) in particular [6].

The Bergen COPD Microbiome study ("MicroCOPD") is a large single-centre study of the airway microbiota, with bronchoscopic sampling of all participants. Data was collected at the Department of Thoracic Medicine, Haukeland University Hospital in Bergen, Norway, between April 2013 and June 2015. The main objective in

(c) The Author(s). 2019 Open Access This article is distributed under the terms of the Creative Commons Attribution 4.0 International License (http://creativecommons.org/licenses/by/4.0/), which permits unrestricted use, distribution, and 
the MicroCOPD study was to examine and compare airway microbiota from subjects without COPD (controls) and subjects with COPD. Some subjects with asthma were also included. The current paper reports response rates, reasons for non-response, motivation for participation, and predictors of participation in the MicroCOPD study.

\section{Methods}

\section{Study design and population}

The MicroCOPD study was a single-centre prospective, observational study carried out in Bergen, Western Norway. The study design has been described previously [7]. A pilot study of eight subjects with COPD was conducted in 2012 for protocol improvement. Participants from the pilot and main study were included in the current analyses. The main study included its first participant on April $11^{\text {th }}, 2013$, with the final study bronchoscopy performed June $5^{\text {th }}, 2015$. The study was conducted in accordance with the declaration of Helsinki and guidelines for good clinical practice. The regional committee of medical ethics approved the project (project number 2011/1307), and all participants provided informed written consent.

Controls and subjects with COPD or asthma were mainly recruited among participants of two previous studies performed by our research groups; the GeneCOPD study from 2003 to 2004 [8] and the Bergen COPD cohort study from 2006 to 2009 [9-12]. In addition, 6 subjects were recruited from outpatient clinics, and 8 subjects were recruited by their own initiative through attention from local media and hospital staff.

All subjects from the two previous studies who still lived in Bergen or the closest surrounding municipalities were eligible for participation. Potential participants were screened by an interview performed by a study physician regarding exclusion criteria for bronchoscopy before giving informed consent. We did not include subjects with increased bleeding risk, subjects with unstable cardiac conditions, or subjects with hypercapnia or hypoxaemia when receiving oxygen supplement [7]. Elderly subjects judged frail by the study physician were excluded. Participation was postponed for subjects that had used antibiotics or oral corticosteroids in the last 14 days, as well as subjects with symptoms of acute exacerbation of COPD.

\section{Data collection}

Subjects that declined participation at the screening interview were asked about their non-response reason. Participants attended the outpatient clinic over one or two days depending on the availability of computed tomography (CT) scanning. A pulmonary and coronary CT scan was offered as part of a concurrent study, and this would be performed prior to bronchoscopy if the participants were scheduled for both procedures. At the day of bronchoscopy, prior to the procedure, participants underwent a structured interview regarding their medical history, respiratory symptoms, smoking habits, medication use, motivation, and exacerbation frequency if they had obstructive lung disease. An open question on motivation was first included in the study questionnaire from the fifth pilot patient, asked immediately prior to the procedure. Additionally, post-bronchodilator spirometry was performed and blood samples were collected.

Diagnoses of COPD and asthma were evaluated by the study physician, based on medical history, symptoms, pulmonary CT scan, and post-bronchodilator spirometry $[13,14]$. Controls were judged to have no sign of airway or lung disease, based on the same information. After all participants were included, a panel of three physicians evaluated the diagnoses for a quality control regarding possible misclassification between controls and subjects with COPD or asthma.

The bronchoscopy procedure was explained in detail to each participant by the study physician immediately prior to the procedure. The procedure was performed with the participant in the supine position, with the option of light sedation (alfentanil, potentially combined with midazolam). Samples were gathered by sterile brushes and bronchoalveolar lavage (BAL) after application of a local anaesthetic agent. Additionally, gathering of bronchial biopsies began in May 2014 . The details of bronchoscopic sampling have been previously published [7]. The average length of the bronchoscopy procedures was $15 \mathrm{~min}$, including bronchoscopies with bronchial biopsies.

\section{Outcomes}

Responders were subjects who accepted the invitation and underwent a bronchoscopy. Non-responders were subjects who did not undergo a bronchoscopy. Late non-responders were subjects who reconsidered an initial decision to participate, or when bronchoscopies were terminated before sampling due to participant discomfort. All non-responders were asked about their reason to decline participation. The response rate was defined as the number of bronchoscopies performed divided by the number of invited subjects.

Participation motives were collected from an open question before bronchoscopy started: "Why did you wish to take part in this project?". Participants could provide more than one motive for participation, thus the overall numbers of motives exceeded the numbers of participants. At the time of analysis we initially merged the unique motives into 16 more principal motives, and then further classified these into three main groups: 1) Altruism was motivation by a wish to help others or a 
wish to continue participation from previous studies, as well as desire to contribute to science. 2) Personal benefit was motivation by a wish to somehow improve own health by participating in the project. 3) Obligation was a subjective feeling of being bound to participate. Subjects without specific reasons were labelled missing. We constructed binary variables "exclusive altruism" and "exclusive personal benefit" by coding them as ' 1 ' if the participant only gave altruism or personal benefit as main motive, respectively. Participants stating both altruism and personal benefit, or altruism/personal benefit and obligation, were coded ' 0 ' on these variables.

\section{Statistical analyses}

All analyses were performed using Stata version 14 [15]. Response rates were stratified by sex and study category (control/obstructive lung disease). Chi-square test or Fisher's exact test was used to compare frequencies of non-response reasons.

Bivariate analyses of responders and non-responders, as well as initial and late non-responders, were performed using parametric (t-test) and non-parametric tests (chi-square test or Fisher's exact test), when judged appropriate. Bivariate logistic regression models were fitted with "exclusive altruism" or "exclusive personal benefit" as outcome. Covariates with $p$ less than 0.20 before adjustment were included in multivariate models. In the logistic regression, age and $\mathrm{FEV}_{1}$ were treated as continuous variables, but divided by 10 to provide ratios for an increase of 10 units. Smoking habits were grouped according to current smoking status (never-, ex-, current-smokers), and we calculated number of pack/ years (cigarettes per day divided by 20, multiplied by years smoking). Never-smokers and ex-smokers were merged into one category in the logistic regression analysis. Lung function was analysed using the percentage of predicted values of $\mathrm{FEV}_{1}$ and FVC, as well as the $\mathrm{FEV}_{1} / \mathrm{FVC}$-ratio. Dyspnoea was classified according to the modified Medical Research Council (mMRC) dyspnoea scale [16].

\section{Results}

\section{Flow chart (Fig. 1)}

In total, 2,205 subjects from the two previous COPD cohorts were considered potential participants for the MicroCOPD study. 1,743 were ineligible, mainly due to death or that the MicroCOPD inclusion period ended (see Additional file 1: Table S1 for details). The total number of invited individuals for bronchoscopy was 462, of whom 323 subjects accepted the invitation. 85 subjects reconsidered their decision to participate, and further three bronchoscopies were terminated before sampling due to participant discomfort.

\section{Response rates}

Since the denominator of the response rate for subjects recruited from outpatient clinics, local media, and hospital staff was unknown, these 14 subjects were excluded from the response-rate analyses. Final response rate for the main study was $50.9 \%$. The response rates in women and men were $44.8 \%(100 / 223)$ and $56.5 \%$ (135/239), respectively $(p=0.01)$. No significant difference in attendance was seen between subjects without obstructive lung disease and subjects with COPD or asthma.

\section{Demographics of responders and non-responders (Table 1)} There was no significant difference in age between responders and non-responders or between early or late responders. Whereas responders and initial non-responders did not differ by study category, there was a larger number of patients among the late non-responders compared with initial non-responders.

\section{Non-response reasons (Table 2)}

Most initial non-responders stated that they feared the discomfort of a bronchoscopy (23.7\%), and together with unspecific fear and worries related to study participation this accounted for $40.2 \%$ of all the initial non-response. The percentage of worries and fears in late non-responders was more than twice as high $(p<0.01)$. Among the initial non-responders there was a higher expression of study fatigue $(10.1 \%$ vs. $2.3 \%, p=0.03)$. A considerable number of the non-responders felt that their own health prevented participation (17.3\% in initial non-responders, and $26.1 \%$ in late non-responders), and most so in subjects with obstructive lung diseases $(p<0.01)$.

\section{Detailed demographics of responders (Table 3)}

The majority of responders were ex-smokers (68.3\%), and a minority were never-smokers (9.6\%). Age and sex were not significantly different between the controls and subjects with COPD. However, there were more ex-smokers and higher number of pack/years, less education, fewer married, more drug use, more comorbidities, as well as higher symptom burden and lower lung function among the subjects with COPD $(p \leq 0.01$, tests not shown).

\section{Motivation (Table 4)}

Personal health benefit was the most common stated principal motive for participation (49.0\%), followed by contribution to science (39.2\%). 39 subjects (15.9\%) also mentioned helping others as motivation. After merging into broader categories, primarily altruism was the main motive stated by most participants (67.3\%), while $52.2 \%$ gave motives considered to be of personal benefit. Only $2.0 \%$ participated out of a sense of obligation. 


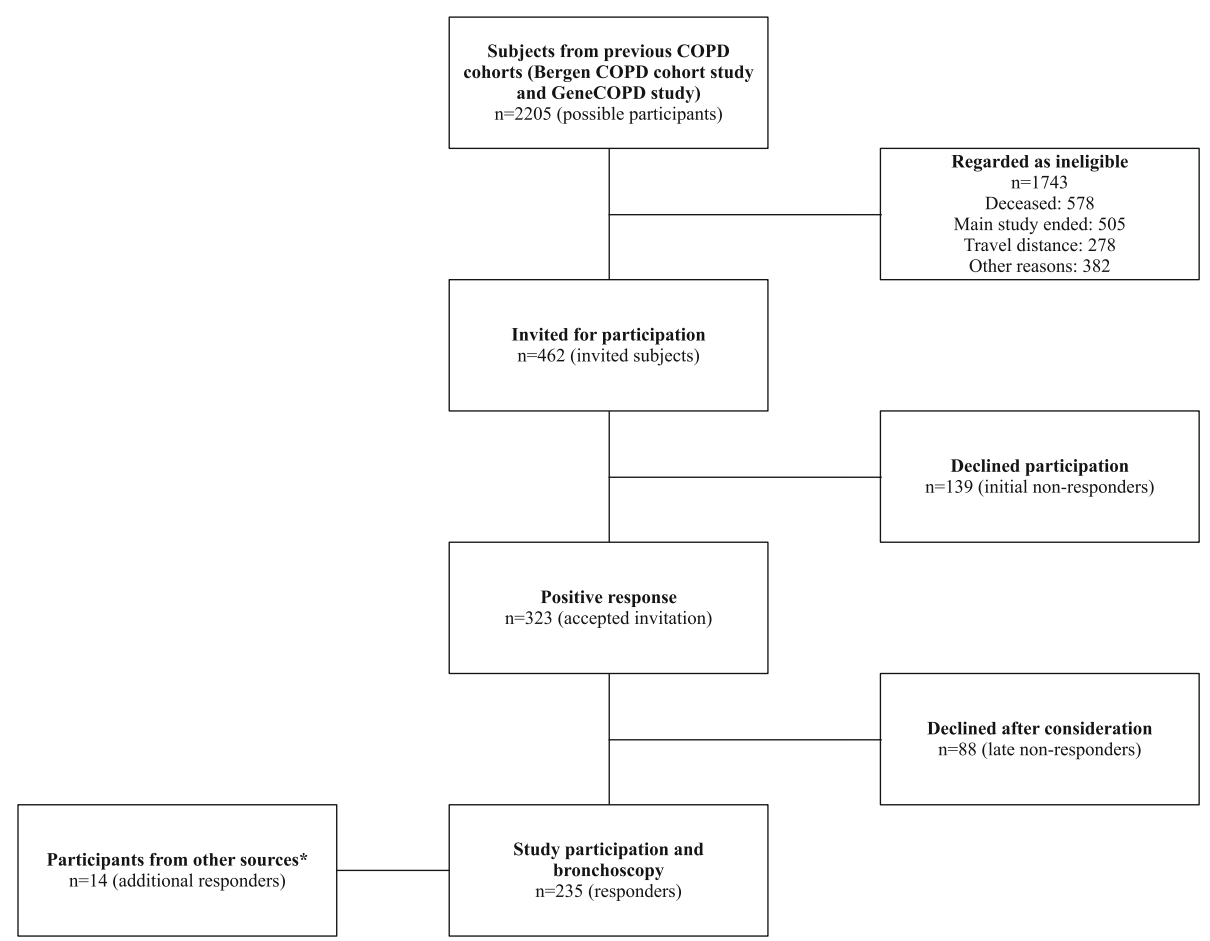

Fig. 1 Flow chart of an observational research bronchoscopy study. ${ }^{*}$ Local media, hospital staff, and outpatient clinics were regarded as other sources

Frequencies on motives were also stratified by participant group, i.e. control, COPD, and asthma (see Additional file 1: Table S2 for details).

Men were less likely to state altruism as their main motive for participation (Fig. 2a, odds ratio (OR) 0.6, $95 \%$ confidence interval $(0.3,0.9))$. This effect was more pronounced in the adjusted model, OR $=0.5(0.3,0.9)$. More subjects with asthma stated personal benefit motives than controls, unadjusted $\mathrm{OR}=4.4(1.5,13.3)$, adjusted $\mathrm{OR}=5.1(1.6,16.0)$ (Fig. 2b). No significant effect was observed by $\mathrm{FEV}_{1}$ in percentage of predicted, age, number of comorbidities, education, or smoking status.

\section{Discussion}

We have reported response rates, non-response reasons, and motives for participation in a large single-centre bronchoscopy study. Response rates were about 50\%, and did not differ between controls and subjects with COPD or asthma. The main reasons for non-response were fear of discomfort from the bronchoscopic procedure, and a subjective feeling of being diseased or too bothered from health issues to participate, especially among subjects with COPD or asthma. Participants were most frequently motivated by altruistic motives, but less so for men.

Table 1 Demographics of responders and non-responders in an observational research bronchoscopy study

\begin{tabular}{|c|c|c|c|c|c|}
\hline \multirow[t]{2}{*}{ Variable } & \multirow{2}{*}{$\begin{array}{l}\text { Responders } \\
n=235\end{array}$} & \multicolumn{2}{|c|}{ Non-responders } & \multirow[t]{2}{*}{$p_{-}^{*}$} & \multirow[t]{2}{*}{$p^{* *}$} \\
\hline & & Initial, $n=139$ & Late, $n=88$ & & \\
\hline Age (SD) & $66.9(7.6)$ & $67.9(8.0)$ & $67.4(7.5)$ & 0.3 & 0.6 \\
\hline Sex & & & & 0.01 & 0.5 \\
\hline Women (\%) & 42.6 & 56.1 & 51.1 & & \\
\hline Men (\%) & 57.4 & 43.9 & 48.9 & & \\
\hline Study category & & & & 0.2 & 0.06 \\
\hline Controls (\%) & 43.0 & 41.7 & 29.6 & & \\
\hline Obstructive lung disease (\%) & 57.0 & 58.3 & 70.4 & & \\
\hline
\end{tabular}

*Difference between responders and all non-responders

**Difference between initial and late non-responders 
Table 2 Self-reported non response-reasons in an observational research bronchoscopy study

\begin{tabular}{|c|c|c|c|c|c|c|}
\hline \multirow[t]{2}{*}{ Reasons } & \multicolumn{3}{|l|}{ Non-responders } & \multicolumn{3}{|l|}{ Study category } \\
\hline & $\begin{array}{l}\text { Initial, } n=139 \\
\text { Frequency (\%) }\end{array}$ & $\begin{array}{l}\text { Late, } \\
n=88 \\
\text { Frequency (\%) }\end{array}$ & $p$ & $\begin{array}{l}\text { Controls, } n=84 \\
\text { Frequency (\%) }\end{array}$ & $\begin{array}{l}\text { OLD, } n=143 \\
\text { Frequency (\%) }\end{array}$ & $p$ \\
\hline Discomfort & $33(23.7)$ & $16(18.2)$ & 0.3 & $19(22.6)$ & $30(21.0)$ & 0.2 \\
\hline Unspecified worries/fear concerning participation & $23(16.5)$ & $30(34.1)$ & $<0.01$ & 19 (22.6) & $34(23.8)$ & 0.08 \\
\hline Disease/health issues & $24(17.3)$ & $23(26.1)$ & 0.1 & $8(9.5)$ & $39(27.3)$ & $<0.01$ \\
\hline Study fatigue & $14(10.1)$ & $2(2.3)$ & 0.03 & $5(6.0)$ & $11(7.7)$ & 0.2 \\
\hline Time constraint & $5(3.6)$ & $5(5.7)$ & 0.5 & $7(8.3)$ & $3(2.1)$ & 0.2 \\
\hline Practical $^{a}$ & $5(3.6)$ & $6(6.8)$ & 0.3 & $5(6.0)$ & $6(4.2)$ & 0.9 \\
\hline Not satisfied with previous study participation & $2(1.4)$ & 0 & 0.5 & 0 & $2(1.4)$ & 0.5 \\
\hline Feeling too old & $2(1.4)$ & 0 & 0.5 & $2(2.4)$ & 0 & 0.2 \\
\hline Refuse to specify & $1(0.7)$ & 0 & 1.0 & $1(1.2)$ & 0 & 0.5 \\
\hline Personal reason & 0 & $3(3.4)$ & 0.06 & $1(1.2)$ & $2(1.4)$ & 1.0 \\
\hline Not specified & $30(21.6)$ & $3(3.4)$ & $<0.01$ & $17(20.2)$ & $16(11.2)$ & 0.7 \\
\hline
\end{tabular}

$O L D$ obstructive lung disease

apractical reflects practical issues for researcher or patient

Table 3 Demographics of participants in an observational research bronchoscopy study

\begin{tabular}{|c|c|c|c|c|}
\hline Variable & All, $n=249$ & Control, $n=103$ & COPD, $n=130$ & Asthma, $n=16$ \\
\hline Age (SD) & $66.3(8.3)$ & $65.3(8.6)$ & $67.2(7.3)$ & $65.5(12.6)$ \\
\hline Sex (men) & $143(57.4)$ & $60(58.3)$ & $76(58.5)$ & $7(43.8)$ \\
\hline Number of medications (SD) & $3.8(3.2)$ & $1.8(1.7)$ & $5.4(3.3)$ & $3.6(2.4)$ \\
\hline Number of comorbidities (SD) & $1.1(1.1)$ & $0.8(1.0)$ & $1.4(1.2)$ & $0.8(0.9)$ \\
\hline $\mathrm{FEV}_{1}, \%$ of predicted (SD) & $78.3(28.2)$ & $103.9(12.3)$ & $56.5(19.2)$ & $90.7(13.3)$ \\
\hline FVC, \% of predicted (SD) & $102.7(18.7)$ & $111.7(13.5)$ & $95.0(19.2)$ & $107.5(16.5)$ \\
\hline $\mathrm{FEV}_{1} /$ FVC-ratio (SD) & $0.6(0.2)$ & $0.7(0.1)$ & $0.5(0.1)$ & $0.7(0.1)$ \\
\hline Pack/years (SD) ${ }^{a}$ & $28.6(20.1)$ & $21.6(16.9)$ & $33.7(20.5)$ & $20.9(22.0)$ \\
\hline \multicolumn{5}{|l|}{ Smoking status (\%) } \\
\hline Daily & $55(22.1)$ & $25(24.3)$ & $30(23.1)$ & $0(0.0)$ \\
\hline Ex-smokers & $170(68.3)$ & $59(57.3)$ & $99(76.2)$ & $12(75.0)$ \\
\hline Never & $24(9.6)$ & $19(18.5)$ & $1(0.8)$ & $4(25.0)$ \\
\hline \multicolumn{5}{|l|}{ Marital status (\%) ${ }^{\mathrm{a}}$} \\
\hline Married/partner & $157(64.3)$ & $79(77.5)$ & $72(57.1)$ & $6(37.5)$ \\
\hline Widowed & $22(9.0)$ & $3(2.9)$ & $16(12.7)$ & $3(18.8)$ \\
\hline Cohabitant & $20(8.2)$ & $5(4.9)$ & $13(10.3)$ & $2(12.5)$ \\
\hline Divorced, lives alone & $33(13.5)$ & $11(10.8)$ & $17(13.5)$ & $5(31.3)$ \\
\hline Single & $12(4.9)$ & $4(3.9)$ & $8(6.4)$ & $0(0.0)$ \\
\hline \multicolumn{5}{|l|}{ Education (\%) } \\
\hline Primary school & $48(19.8)$ & $12(11.8)$ & $35(27.8)$ & $1(6.7)$ \\
\hline Upper secondary/high school & $125(51.4)$ & $52(51.0)$ & $67(53.2)$ & $6(40.0)$ \\
\hline 3 years or more of higher education & $70(28.8)$ & $38(37.3)$ & $24(19.1)$ & $8(53.3)$ \\
\hline \multicolumn{5}{|l|}{ mMRC Grade 2 and higher (\%) } \\
\hline Grade 2 level ground & $30(54.6)$ & $3(100)$ & $27(52.9)$ & $0(0.0)$ \\
\hline Grade 3100 m & $18(32.7)$ & $0(0.0)$ & $17(33.3)$ & $1(100)$ \\
\hline Grade 4 resting dyspnoea & $7(12.7)$ & $0(0.0)$ & $7(13.7)$ & $0(0.0)$ \\
\hline
\end{tabular}


Table 4 Motives reported by the $245^{a}$ participants who gave motives in an observational research bronchoscopy study

\begin{tabular}{|c|c|c|}
\hline Motives & $\mathrm{n}$ & Percentage \\
\hline Primarily altruism ${ }^{\mathrm{b}}$ & 165 & 67.3 \\
\hline Previous participation & 23 & 9.4 \\
\hline Contribute to science & 96 & 39.2 \\
\hline Help others & 39 & 15.9 \\
\hline Give back (for previous participation) & 7 & 2.9 \\
\hline $\begin{array}{l}\text { Generally positive (to examination or } \\
\text { participation and "yes-human") }\end{array}$ & 6 & 2.4 \\
\hline Social responsibility & 3 & 1.2 \\
\hline $\begin{array}{l}\text { COPD in family/among friends } \\
\text { (including risk of COPD in family) }\end{array}$ & 19 & 7.8 \\
\hline Available time & 3 & 1.2 \\
\hline Primarily personal benefit ${ }^{b}$ & 128 & 52.2 \\
\hline Personal health benefit & 120 & 49.0 \\
\hline $\begin{array}{l}\text { Experience the discomfort of } \\
\text { bronchoscopy }\end{array}$ & 1 & 0.4 \\
\hline Challenge & 1 & 0.4 \\
\hline Curiosity & 14 & 5.7 \\
\hline Fun & 1 & 0.4 \\
\hline Primarily obligation ${ }^{\mathrm{b}}$ & 5 & 2.0 \\
\hline $\begin{array}{l}\text { Acquaintance (in study, working with and } \\
\text { was connected to the study or asked by) }\end{array}$ & 4 & 1.6 \\
\hline Trust in authority/research & 1 & 0.4 \\
\hline Missing & 20 & 8.2 \\
\hline
\end{tabular}

a Participation was not part of the questionnaire for the first four participants bUnique motives are categorised into three main motives (in italic) by merging the unique motives listed below the main motive. The frequency (n) of main motives is not equal to the sum of each principal motive because a subject stating both "personal health benefit" and "challenge" would result in two observations in principal motives, but just one after merging

Given the invasiveness of the involved procedures, a response rate of $50 \%$ is not remarkably low. Little data exists on participation in research bronchoscopy studies [6]. Neither of seven Norwegian respiratory health surveys studies between 1965 and 1999 included a bronchoscopy, but baseline response rates varied from 68 to $90 \%$ [17]. Once attending, only 5\% of attendants did not complete their participation [17]. In the current study, $27.2 \%(88 / 323)$ reconsidered their decision, suggesting higher rates of reconsideration with more invasive procedures.

A trend towards lower participation rates has been observed in Norwegian studies over time $[17,18]$. This trend could at worst lead to selection bias and compromised external validity. In general, young, single men living in urban areas are the least likely to participate in social science surveys, while older women are the most willing [18]. In the current study, more men than women were responders. Experiences from clinical work suggest that women worry more about clinical procedures, and this could serve as a possible explanation for the observed difference. Additionally, more men were motivated by perceived personal benefit. If this observation stands true, one could speculate that male motivation is more easily satisfied by participation in a clinical study involving an actual diagnostic procedure, than participation in a questionnaire study. We observed no difference in mean age between responders and non-responders, but younger individuals were omitted from the current study, and frail elders were excluded. In another Norwegian study on respiratory health, non-response was related to lower age, rural habitation, and smoking habits [19]. Response rates from the current study will help researchers scale the number of invited subjects, aiming to recruit a sufficient number of participants, in order to avoid type II errors. These numbers can also be of value when investigators seek funding and ethics approval, providing precise information regarding the inclusion process.

Knowledge of reasons for non-response could guide researchers to provide precise information regarding the procedure during recruitment, which in turn might influence the willingness to participate. Observed difference in worries/fear between initial and late non-responders suggests that participants become frightened during the waiting time. Information on relevant discomfort should always be disclosed at first contact to avoid unreasonably procedural fear, and unnecessary waiting time before scheduled procedures should be avoided, both for research and clinical purposes. This will reduce costs and planning of non-performed procedures.

In agreement with the literature, we could categorise motives for participation into three groups, namely personal benefit, altruism, and obligation [6], although the review stated obedience to the authority of the researchers as an own group. Only one subject claimed trust in authority/research to be of importance in the current study. This discrepancy with previous studies might reflect both cultural differences and differences in health care organisation. Furthermore, patients are increasingly making their own health decisions [20], which might have changed the view of physicians as authorities.

We observed that women expressed more altruistic motives than men. In concordance with the current study, a meta-analysis on altruism and gender by Rand et al. showed women to be more intuitively altruistic, and men to be more selfish both intuitively and after consideration [21]. Our observation that subjects with asthma tend to report personal benefit needs to be interpreted with some caution. There were few subjects with asthma in our study, and they were recruited in a non-controlled manner.

Our results indicate that providing information on future implications of research can promote participation 


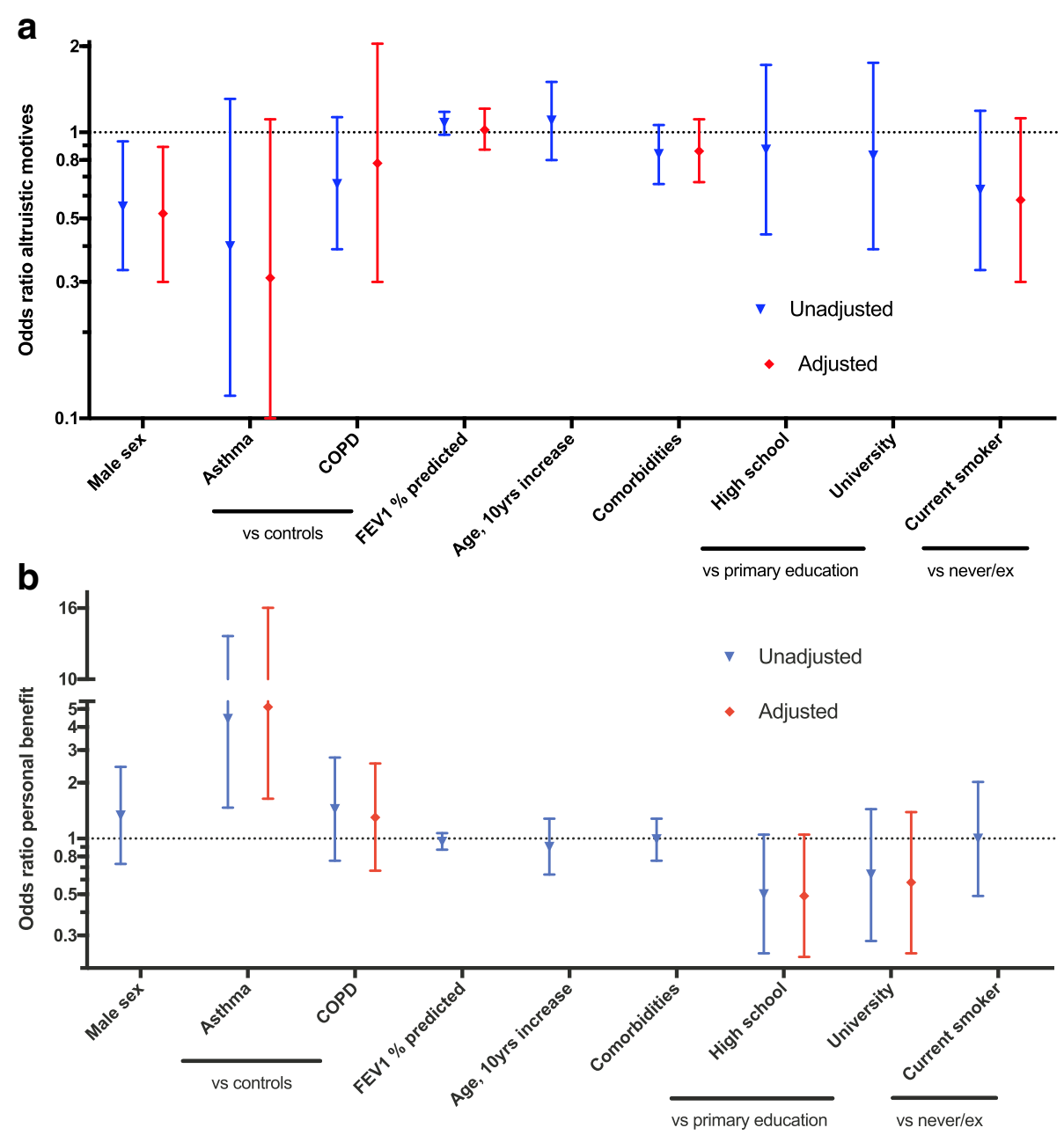

Fig. 2 Logistic regression on a) exclusive altruism- and b) exclusive personal benefit-variables in an observational research bronchoscopy study

by appealing to a desire to contribute to science and future health care. Emphasising potential health benefits of study participation would probably have an even greater effect, but this warrants caution. Screening effects of bronchoscopy are not known. Also, there is a small complication risk associated with the procedure [4]. Participants were offered participation also in a concurrent study wherein a CT scan was offered, however participation in either study was not dependent on participation in the other. Thus, no exclusive, immediate benefit was received for the participants in the MicroCOPD study. Even though this was clearly stated in the written consent, almost half of the final participants stated personal benefit as an important motive. Participants' expectation of perceived health benefit from participation is well known from the literature, even though no such benefit should be expected [5, 22], also where this is clearly stated by the research team [23]. Thus, we believe that participants' perceived personal benefit in observational studies should be examined more thoroughly in future studies.
The MicroCOPD study is, to our knowledge, the largest single-centre lung microbiome study performed to date. We had extensive demographics on responders, and reliable results on motivation and non-response reasons. Some potential weaknesses deserve mentioning. Firstly, due to ethical and practical reasons, demographics on non-responders were sparse, and a considerable proportion of non-responders did not give any reason for their decline. Secondly, albeit a large study, the heterogeneity of the participants may have obscured the finding of important predictors of participation and motivation. Thirdly, an in-depth interview could have provided more insight into the details of non-response and motivation. Finally, most participants had already shown a willingness to take part in previous studies. Hence, they might be more prone to take part than a general population, generating some degree of selection bias. On the other hand, "study fatigue" might have lowered the participation rate in the current study. 


\section{Conclusions}

The response rate for research bronchoscopy in our study was $50 \%$, and did not differ between controls and subjects with COPD or asthma. Non-responders refused participation mainly due to procedural fear. In contrast, responders were driven by perceived personal benefit, but a large proportion did also participate to help others and contribute to science. Our findings underline the importance of providing comprehensive information about the procedures. This might serve to avoid refusal on a possible misunderstood risk assessment, and to secure inclusion of a sufficient number of well-informed participants.

\section{Additional file}

Additional file 1: Table S1. Reasons for ineligibility in an observational research bronchoscopy study, $n=1743$. Table S2. Motives reported by the $245^{\mathrm{a}}$ participants who gave motives in an observational research bronchoscopy study stratified by participant group. (PDF $96 \mathrm{~kb}$ )

\section{Abbreviations}

"MicroCOPD": The Bergen COPD Microbiome study; BAL: Bronchoalveolar lavage; COPD: Chronic obstructive pulmonary disease; CT: Computed tomography; OLD: Obstructive lung disease

\section{Acknowledgements}

Not applicable

\section{Funding}

This work was supported by the Medical Student Research Programme at the University of Bergen, Norway.

\section{Availability of data and materials}

The dataset generated and/or analysed during the current study is not publicly available due to confidentiality, but is available from the corresponding author on reasonable request.

\section{Additional information}

An early version of this work was presented in poster form last September $10^{\text {th }} 2017$ at the European Respiratory Society International Congress in Milan.

\section{Authors' contributions}

EMHM had full access to all of the data in the study and takes responsibility for the integrity of the data and the accuracy of the data analysis. EMHM, TMLE, EOL, EN, SL, and RN participated in different aspects of data collection. EMHM, TMLE, EOL, EN, PSB, SL, and RN contributed substantially to the study design, data analysis and interpretation, and the writing of the manuscript. All authors read and approved the final manuscript.

\section{Ethics approval and consent to participate}

The study was conducted in accordance with the declaration of Helsinki and guidelines for good clinical practice. The regional committee of medical ethics approved the project (project number 2011/1307), and all participants provided informed, written consent.

\section{Consent for publication}

Not applicable.

\section{Competing interests}

EMHM, EOL, EN, PSB and SL declare no conflict of interest. TMLE reports grants from Western Norway Regional Health Authority during the conduct of the study, and personal fees from Boehringer Ingelheim and AstraZeneca outside the submitted work. RN reports grants from GlaxoSmithKline during the conduct of the study, and grants from Boehringer Ingelheim, grants and personal fees from AstraZeneca, grants from Novartis, and personal fees from GlaxoSmithKline outside the submitted work.

\section{Publisher's Note}

Springer Nature remains neutral with regard to jurisdictional claims in published maps and institutional affiliations.

\section{Author details}

${ }^{1}$ Department of Clinical Science, University of Bergen, N-5021 Bergen, Norway. ${ }^{2}$ Department of Thoracic Medicine, Haukeland University Hospital, N-5021 Bergen, Norway.

Received: 5 October 2018 Accepted: 5 March 2019

Published online: 02 May 2019

References

1. Beck JM, Schloss PD, Venkataraman A, Twigg H 3rd, Jablonski KA, Bushman FD, et al. Multicenter comparison of lung and Oral microbiomes of HIVinfected and HIV-uninfected individuals. Am J Respir Crit Care Med. 2015; 192(11):1335-44.

2. Morris A, Beck JM, Schloss PD, Campbell TB, Crothers K, Curtis JL, et al. Comparison of the respiratory microbiome in healthy nonsmokers and smokers. Am J Respir Crit Care Med. 2013;187(10):1067-75.

3. Shenoy MK, Iwai S, Lin DL, Worodria W, Ayakaka I, Byanyima P, et al. Immune response and mortality risk relate to distinct lung microbiomes in patients with HIV and pneumonia. Am J Respir Crit Care Med. 2017; 195(1):104-14.

4. Leiten EO, Martinsen EMH, Bakke PS, Eagan TML, Grønseth R. Complications and discomfort of bronchoscopy: a systematic review. European clinical respiratory journal. 2016;3(1):33324.

5. Patel D, Akporobaro A, Chinyanganya N, Hackshaw A, Seale C, Spiro SG, et al. Attitudes to participation in a lung cancer screening trial: a qualitative study. Thorax. 2012;67(5):418-25.

6. Martinsen EM, Leiten EO, Bakke PS, Eagan TM, Gronseth R. Participation in research bronchoscopy: a literature review. European clinical respiratory journal. 2016;3:29511.

7. Grønseth R, Haaland I, Wiker HG, Martinsen EMH, Leiten EO, Husebø G, et al. The Bergen COPD microbiome study (MicroCOPD): rationale, design, and initial experiences. European clinical respiratory journal. 2014;1(1):26196.

8. Sorheim IC, Johannessen A, Grydeland TB, Omenaas ER, Gulsvik A, Bakke PS. Case-control studies on risk factors for chronic obstructive pulmonary disease: how does the sampling of the cases and controls affect the results? Clin Respir J. 2010;4(2):89-96

9. Eagan TM, Aukrust P, Bakke PS, Damas JK, Skorge TD, Hardie JA, et al. Systemic mannose-binding lectin is not associated with chronic obstructive pulmonary disease. Respir Med. 2010;104(2):283-90.

10. Eagan TM, Aukrust P, Ueland T, Hardie JA, Johannessen A, Mollnes TE, et al. Body composition and plasma levels of inflammatory biomarkers in COPD. Eur Respir J. 2010;36(5):1027-33.

11. Eagan TM, Damas JK, Ueland T, Voll-Aanerud M, Mollnes TE, Hardie JA, et al. Neutrophil gelatinase-associated lipocalin: a biomarker in COPD. Chest. 2010;138(4):888-95

12. Eagan $T M$, Ueland $T$, Wagner $P D$, Hardie JA, Mollnes TE, Damas JK, et al. Systemic inflammatory markers in COPD: results from the Bergen COPD cohort study. Eur Respir J. 2010;35(3):540-8.

13. Global Initiative for Chronic Obstructive Lung Disease. Global Strategy for the Diagnosis, Management, and Prevention of Chronic Obstructive Pulmonary Disease, 2019 [cited December 2018]. Available from: https:// goldcopd.org/.

14. Global Initiative for Asthma. Global Strategy for Asthma Management and Prevention, 2018 [cited December 2018]. Available from: https://ginasthma. org/.

15. StataCorp. Stata [cited April 2018]. Available from: https://www.stata.com.

16. MDCalc. mMRC (Modified Medical Research Council) Dyspnea Scale [cited September 2018]. Available from: https://www.mdcalc.com/mmrc-modifiedmedical-research-council-dyspnea-scale.

17. Gulsvik A, Humerfelt S, Bakke PS, Omenaas ER, Lehmann S. Norwegian population surveys on respiratory health in adults: objectives, design, methods, quality controls and response rates. Clin Respir J. 2008;2(Suppl 1):10-25. 
18. ScienceNordic. Fewer willing to participate in surveys [cited October 2017]. Available from: http://sciencenordic.com/fewer-willing-participate-surveys.

19. Abrahamsen R, Svendsen MV, Henneberger PK, Gundersen GF, Toren K, Kongerud J, et al. Non-response in a cross-sectional study of respiratory health in Norway. BMJ Open. 2016;6(1):e009912.

20. Charles C, Gafni A, Whelan T. Shared decision-making in the medical encounter: what does it mean? (or it takes at least two to tango). Soc Sci Med. 1997;44(5): 681-92.

21. Rand DG, Brescoll VL, Everett JA, Capraro V, Barcelo H. Social heuristics and social roles: intuition favors altruism for women but not for men. J. Exp. Psychol. Gen. 2016;145(4):389-96.

22. Mtunthama N, Malamba R, French N, Molyneux ME, Zijlstra EE, Gordon SB. Malawians permit research bronchoscopy due to perceived need for healthcare. J Med Ethics. 2008;34(4):303-7.

23. Lipman MC, Stobbs D, Madge S, Miller R, Johnson MA. Research bronchoscopies do not adversely affect HIV-infected individuals' future health-care decisions. Chest. 1998;114(1):284-90.

Ready to submit your research? Choose BMC and benefit from:

- fast, convenient online submission

- thorough peer review by experienced researchers in your field

- rapid publication on acceptance

- support for research data, including large and complex data types

- gold Open Access which fosters wider collaboration and increased citations

- maximum visibility for your research: over $100 \mathrm{M}$ website views per year

At $\mathrm{BMC}$, research is always in progress.

Learn more biomedcentral.com/submissions 